206

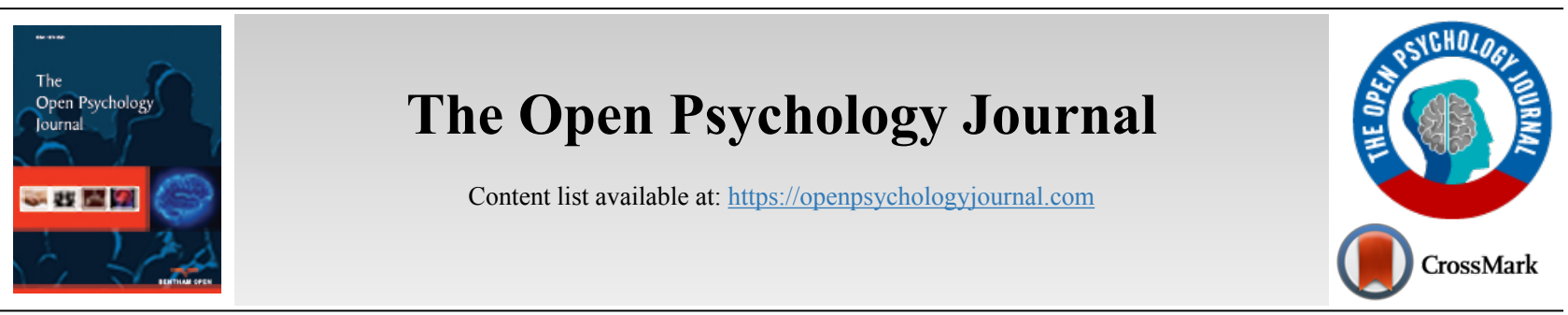

\title{
LETTER
}

\section{Gratitude Enhances Work Engagement through Reduced Perception of Damage: A Case Study in Nepals' Earthquake Disaster}

\author{
Kyungil Kim ${ }^{1, *}$, Bojindra Prasad Tulachan ${ }^{2}$, Yung-Ho Cho ${ }^{3}$ and Tae Hoon $\mathrm{Kim}^{4}$ \\ ${ }^{1}$ Department of Psychology, Ajou University, Suwon, South Korea \\ ${ }^{2}$ Department of Global Business Management, KC University, Seoul, South Korea \\ ${ }^{3}$ Department of Business Administration, Ajou University, Suwon, South Korea \\ ${ }^{4}$ Department of Psychology, Kyungnam University, Changwon, South Korea
}

\begin{abstract}
:
How important gratitude is in terms of helping people to overcome their mental discomfort and behave adaptively? Conflicting evidence has appeared about the effects of gratitude on work engagement, and other aspects of life. In the present study, gratitude intervention was introduced to test it in the Nepali population who experienced a natural disaster, the Gorkha earthquake in 2015. Positive and negative affect, work engagement, and perceived damage were measured before, during, and after the intervention. Participants were sampled from the employees of 5-star hotel in Kathmandu valley and were assigned to one of the three conditions: Gratitude, Job Diary, and No Exposure. In gratitude, they were asked to write the names of 3 grateful people. Participants of Job Diary were instructed to write 3 major duties. No intervention was given to participants in No Exposure. This exercise lasted for two weeks. Only those in Gratitude showed increased positive affect and work engagement and decreased negative affect during this intervention. These positive changes seemed related to decreased perceived damage of a natural disaster. Even though there have been mixed results about the effect of gratitude, findings of the present study showed that it is robust even against a real disaster. Conducting research with survivors against natural disasters is extremely difficult, but more effort should be made with those who have similar experiences.
\end{abstract}

Keywords: Gratitude, Gratitude intervention, Affect, Work engagement, Damage perception, Natural disaster.

\begin{tabular}{l|l|l|r} 
Article History & Received: March 11, 2020 & Revised: May 26, 2020 & Accepted: June 9, 2020
\end{tabular}

\section{INTRODUCTION}

Gratitude has been getting a great deal of attention practically as well as theoretically in various areas. Gratitude is difficult to define because it has a number of different meanings depending on the context. For example, gratitude has been differently conceptualized, such as a moral virtue, an attitude, an emotion, a habit, a personality trait, a coping response, and even a life orientation $[1,2]$. It is beyond the purpose of this study, but we would like to define gratitude as the appreciation of valuable and meaningful things in one's life [3].

Research has shown that people can deliberately cultivate gratitude and increase their own well-being and happiness [4]. The relationship between gratitude and well-being has been well documented. Being grateful was helpful for college students to reappraise their unpleasant emotional memories and to process them in an adaptive way [5]. Those with dispositional gratitude were likely to reframe negative events,

\footnotetext{
* Address correspondence to this author at the Department of Psychology, Ajou University, 206 Worldcup-ro, Yeongtong-gu, Suwon 16499, Korea; E-mail: kyungilkim@ajou.ac.kr
}

seeing their life more meaningfully and comprehensibly [6]. Gratitude also decreased stress levels over time and brought a better sleep, leading to a healthier condition [7, 8]. A similar result was found in an organizational setting: those with gratitude interventions showed a tendency of having a positive view and selectively focusing on the good side [9]. Furthermore, an expression of gratitude is associated with increased energy, optimism, and empathy [10].

Psychological impairment from traumatic events, such as death of a family member, divorce, war, terrorism, natural disaster, etc., is another important topic in gratitude research. For students with a history of trauma, the more grateful they were, the lower levels of Post-Traumatic Stress Disorder (PTSD) were reported [11]. A negative association between gratitude and PTSD symptoms was observed for female students with histories of trauma [12]. The reported level of gratitude was higher for Vietnam veterans without PTSD than those with PTSD [13].

Meanwhile, those who experienced natural disasters were very vulnerable to psychological impairment. Many studies with survivors against natural disasters showed gratitude is 
helpful for them to cope with mental discomfort. A study with police officers from Louisiana, experiencing Hurricane Katrina, showed an association between gratitude and higher life satisfaction and lower depressive symptoms [14]. Gratitude was a direct indicator of PTS symptoms and global distress for earthquake survivors in Indonesia [15]. Even post-traumatic growth was shown with those experiencing the Ya'an earthquake [16].

Given strong associations between gratitude and wellbeing, researchers focused on gratitude intervention to explore the possible causality. Participants with gratitude interventions were asked to keep a diary of listing grateful things, do grateful contemplation, or express their gratitude $[2,17]$. Among those, listing grateful things is relatively easier to follow and enjoyable. Moreover, even after the experiment is completed, participants are likely to continue this exercise. Thus, this type of intervention is used most often in gratitude intervention studies [2].

With gratitude intervention and thereby exercise, one can expect an association with positive affect, higher work engagement, etc. For example, gratitude exercise led people to have increased positive thinking at their work and about work engagement [4]. For those exposed to painful events, gratitude interventions have been reported successful, increasing the levels of happiness, satisfaction, positive affect, well-being, etc. [2]. With gratitude interventions, physical symptoms were reported less [4], a negative association appeared between physical symptoms and gratitude [18], and a body image was improved for those with bulimia nervosa [19].

In an organizational setting, as stated above, participants with gratitude interventions were more likely to reframe adverse events and see good things from the negatives [9], which could increase their positive affect and work engagement. This is important in terms of having their employees return to their workplace, helping them to recover from traumatic events. However, improvement of work engagement did not appear in all of the studies. Those exposed to Hurricane Katrina showed a higher level of gratitude after the intervention and 6-week follow-up, but no improvement in work engagement. Therefore, it is worthwhile to find out whether or not gratitude interventions would be expected to lead to a higher level of work engagement.

From previous findings, gratitude interventions seemed to have people see a brighter side and help people overcome traumatic events. However, not all investigators have confirmed associations between gratitude and its positive effect in emotion and behavior, e.g., for those with PTSD [13], divorced middle-aged women [20], children [21], and those who experienced natural disaster [15].

These mixed results regarding the effectiveness of gratitude interventions might have come from the selection of a control group. Most of the previous studies with gratitude intervention seemed to have improper control conditions, such as listing daily hassles [4], writing about the structure of the living room [22], writing about early memories [23], and even no treatment control group [24]. There were only a few studies with a control group, where participants kept their daily records
[19] or completed a worry diary [25]. As suggested by Wood et al. [2], it would be more informative if a comparison were made against a proper control group, such as a no-treatment group and/or a group with a regular task. Evaluation of gratitude interventions with these control groups would help demonstrate its true effect. It would also provide a hint as to how individuals can utilize it for their work as well as for their daily lives. However, no study has used the above-mentioned control group for gratitude interventions with survivors from a natural disaster, such as an earthquake.

The present study was designed to find out whether gratitude is truly helpful for enhancing work engagement as well as subjective well-being and, more importantly, if it would work in a real situation. To address these questions together, a two-month study in Nepal was conducted with those who experienced a well-known natural disaster. On 25 April 2015, Nepal earthquake (Nepali: Bhukampa) (also known as the Gorkha earthquake) killed over 8,000 people and injured more than 21,000 . It was the worst natural disaster to strike Nepal since the 1934 Nepal-Bihar earthquake.

Given a link between gratitude and improvement in psychological impairment from findings of previous studies, the present study investigated whether or not similar results would appear with survivors from a natural disaster in Nepal. More importantly, the effect of gratitude interventions was explored to see if it would lead to improved images of negative events and a higher level of work engagement. Thus, it was hypothesized that gratitude intervention would have earthquake survivors create positive thinking, enhance their work engagement, and decrease their perception of damage based on the positive change in their mind.

\section{METHODS}

This study was conducted from the $1^{\text {st }}$ week of January to the end of February. Gratitude intervention (Gratitude) was introduced by having participants list their 3 grateful people per day. A comparison was made with a control condition where they list their 3 major duties (Job Diary) and a notreatment condition (No Exposure).

\subsection{Participants}

One hundred and eighty employees of three 5-star level hotels (Malla, Yak \& Yeti, and Crown Plaza KathmanduSoaltree) participated in this study (60 participants from each hotel). They were randomly assigned to one of the following three groups: Gratitude, Job Diary, and No Exposure. Throughout this study, 4, 8, and 7 participants from each group were dropped out for personal reasons. Thus, the number of participants ended up being 161 (56, 52, and 53 for Gratitude, Job Diary, and No Exposure, respectively).

Those in the three hotels were overall homogeneous in demographic information, such as age, gender distribution, work-type, income level, and education level. Detailed demographic information is as follows. Age ranged from $20 \mathrm{~s}$ $(26 \%), 30$ s $(41 \%)$, to 40 s $(33 \%)$, and there were $83 \%$ of males and $17 \%$ of females. In terms of work-type, $81.4 \%$ were rank and file employees, and $18.6 \%$ were supervisors/managers. A range of monthly income was relatively evenly distributed: in 
USD, 50 to 90 (20\%), 90 to 140 (24\%), 140 to 190 (25\%), and over $190(30 \%)$. So was their education level: under Small Learning Community (SLC) (18\%), SLC graduates (21\%), intermediate graduates $(23 \%)$, bachelor's degree, and beyond $(39 \%)$.

\subsection{Measures}

\subsubsection{Positive and Negative Affect}

The Job-related Affective Well-Being Scale (JAWS) [26] was administered to measure participants' positive and negative affect. This scale measures how often participants have experienced positive and negative affects at work over the past 30 days. The internal consistencies of positive affect were $0.93,0.97$, and 0.93 , and those of negative affect were 0.94 , 0.97 , and 0.96 for Pre-Intervention (Phase 1), Intervention (Phase 2), and Post-Intervention (Phase 3), respectively.

\subsubsection{Work Engagement}

Work engagement was measured with the Utrecht Work Engagement Scale (UWES) [27], which consists of 17 items. The UWES quantifies vigor, dedication, and absorption at work, using questions, such as "At my work I feel bursting with energy," "I am enthusiastic about my work," and "I get carried away by my work." This scale was formatted in a 5point Likert scale to meet the positive and negative affect. The internal consistencies were $0.92,0.96$, and 0.95 for PreIntervention (Phase 1), Intervention (Phase 2), and PostIntervention (Phase 3), respectively.

\subsubsection{Perceived Damage}

One question was developed to measure the perception of physical damage with a 5-point Likert scale. The question was "To what extent did the earthquake April, 2015 damage the Kathmandu valley?" (a greater number indicates more serious damage). This question was given at each phase to examine whether or not the perceived damage would change over the 3 phases.

\subsection{Procedure}

The study was conducted from the $1^{\text {st }}$ week of January 2016 to $4^{\text {th }}$ week of February. During the $1^{\text {st }}$ week of January 2016, an initial survey was distributed and collected for all groups (Pre-Intervention, Phase 1). In the 2nd and 3rd weeks of January, the intervention was introduced for gratitude and job diary groups. Then the second survey was conducted for all groups (Intervention, Phase 2). After 1 month, the third survey was carried out for all groups (Post-Intervention, Phase 3). Participants completed the JAWS [26], the UWES [27], and the question of their perceived damage at three different points of time (Phases 1, 2, and 3) during this period.

\subsubsection{Pre-Intervention (Phase 1)}

In the beginning, two representatives from each hotel were selected, who helped to place informed consent and recruitment forms. They were put in public places and were distributed together to the participants with the help of the representatives because of their busy work schedules. Participants put their consent form and surveys into the return box after they finished.

\subsubsection{Gratitude and Job Diary Interventions (Phase 2)}

In gratitude, the participants were asked to carry out the "Three Good Things in Life" intervention exercise. In this exercise, 5 to 10 minutes before sleeping, they were asked to remember 3 nice people who were thankful, grateful, and appreciative of at their workplace or outside during that particular day. Then they had to write the names of those 3 people in their diary and return it to the representatives the next day. For this intervention exercise, a pen and a diary were provided to every participant. This exercise was regularly performed for two weeks.

In Job Diary, on the other hand, the participants were asked to write 3 major duties they performed every day. All other procedures were the same as those in gratitude. This intervention exercise also lasted for two weeks at the same timing to the Gratitude group. At the end of the exercise, the same survey questionnaires were distributed to all the participants in all the groups.

\subsubsection{Post-Intervention (Phase 3)}

After a month of the completion of the intervention exercises, all the participants of the three groups completed the same survey questionnaires. At the closure of the research project, each participant was provided a gift equivalent to $\$ 10$ and briefed about experimental procedures and expected results. Note that participants in the No Exposure group were given no intervention and merely responded to the same questionnaires in the times corresponding to each phase.

\section{RESULTS}

The overall results of positive and negative affects, perceived damage, and work engagement of Gratitude, Job Diary, and No Exposure groups are presented in Table $\mathbf{1}$. Specifically, no difference in positive or negative affect and in work engagement was found through 3 phases in Job Diary and No Exposure (in all cases, $\mathrm{p}>.25$ ). In contrast, significant increases in the positive affect and work engagement and a significant decrease in negative affect between phases 1 and 2 in gratitude were observed, as can be seen in Fig. (1).

Table 2 presents correlations among the study variables for Gratitude, Job Diary, and No Exposure groups at each phase. Inspection of the correlation matrices showed a relatively similar pattern for three groups at phase 1 (pre-intervention) and at phase 3 (post-intervention), but a clear difference at phase 2 (during intervention). At phase 1, work engagement showed significant correlations with both effects and perceived damage did not show significant correlations in most cases. At phase 2, only for gratitude, perceived damage had strong correlations with the dependent variables. At phase 3, perceived damage did not show significant correlations in most cases. 
Table 1. Mean scores of each dependent variable at each phase and its differences.

\begin{tabular}{|c|c|c|c|c|c|}
\hline variables & Condition & \begin{tabular}{|c|} 
Phase 1 \\
Pre-intervention \\
\end{tabular} & \begin{tabular}{|c|} 
Phase 2 \\
After-intervention \\
\end{tabular} & $\begin{array}{c}\text { Phase } 3 \\
\text { Post-intervention } \\
\end{array}$ & $\begin{array}{c}F(p) \\
{[95 \% \text { C.I. of a-b, } 95 \% \text { C.I. of a-c] }}\end{array}$ \\
\hline \multirow{3}{*}{ Perceived Damage } & Gratitude & $3.64(.94)$ & $2.82(.74)$ & $2.64(.48)$ & $\begin{array}{c}20.871(<.001) \\
{[.51 \sim 1.13, .70 \sim 1.31]} \\
\end{array}$ \\
\hline & Job Diary & $3.94(.83)$ & $3.77(.92)$ & $3.83(1.00)$ & $\begin{array}{c}.623(.538) \\
{[-.14 \sim .49,-.20 \sim .43]} \\
\end{array}$ \\
\hline & No Exposure & $3.98(.84)$ & $3.92(.85)$ & $3.87(.81)$ & $\begin{array}{c}.332(.718) \\
{[-.26 \sim .37,-.20 \sim .43]}\end{array}$ \\
\hline \multirow{3}{*}{$\begin{array}{l}\text { Positive } \\
\text { Affect }\end{array}$} & Gratitude & $3.51(.71)$ & $4.82(.29)$ & $4.81(.21)$ & $\begin{array}{c}82.949(<.001) \\
{[-1.51 \sim-1.11,-1.51 \sim-1.08]}\end{array}$ \\
\hline & Job Diary & $3.45(.85)$ & $3.22(.60)$ & $3.30(.59)$ & $\begin{array}{c}4.104(.018) \\
{[.03 \sim .44,-.08 \sim .37]} \\
\end{array}$ \\
\hline & No Exposure & $3.36(.81)$ & $3.50(.67)$ & $3.57(.61)$ & $\begin{array}{c}2.361(.098) \\
{[-.34 \sim .07,-.43 \sim .01]}\end{array}$ \\
\hline \multirow{3}{*}{ Negative Affect } & Gratitude & $2.21(.75)$ & $1.12(.29)$ & $1.18(.12)$ & $\begin{array}{c}49.069(<.001) \\
{[.87 \sim 1.31, .82 \sim 1.25]} \\
\end{array}$ \\
\hline & Job Diary & $2.57(.91)$ & $2.69(.64)$ & $2.90(.70)$ & $\begin{array}{c}11.477(<.001) \\
{[-.36 \sim .10,-.56 \sim-.11]} \\
\end{array}$ \\
\hline & No Exposure & $2.05(.77)$ & $2.18(.87)$ & $2.18(.85)$ & $\begin{array}{c}.683(.507) \\
{[-.36 \sim .09,-.35 \sim .09]} \\
\end{array}$ \\
\hline \multirow{3}{*}{ Work Engagement } & Gratitude & $3.73(.74)$ & $4.74(.59)$ & $4.68(.71)$ & $\begin{array}{c}50.030(<.001) \\
{[-1.21 \sim-.81,-1.17 \sim-.72]}\end{array}$ \\
\hline & Job Diary & $3.51(.74)$ & $3.20(.44)$ & $3.30(.50)$ & $\begin{array}{c}4.438(.013) \\
{[.10 \sim .52,-.03 \sim .44]} \\
\end{array}$ \\
\hline & No Exposure & $3.31(.77)$ & $3.28(.60)$ & $3.23(.49)$ & $\begin{array}{c}.332(.718) \\
{[-.32 \sim .15,-.22 \sim .11]}\end{array}$ \\
\hline
\end{tabular}

Notes. Standard deviations are in parentheses.

$\mathrm{N}=56$ for Gratitude, $\mathrm{N}=52$ for Job Diary, and N=53 for No Exposure. 'a-b' and 'a-c' denote the differences between Phase 1 and Phase2 and between Phase 1 and Phase 3 , respectively.

Table 2. Correlations among dependent variables for each group at each phase.

\begin{tabular}{|c|c|c|c|c|c|c|c|c|c|c|c|c|c|}
\hline & & \multicolumn{4}{|c|}{ Phase 1} & \multicolumn{4}{|c|}{ Phase 2} & \multicolumn{4}{|c|}{ Phase 3} \\
\hline & & $\mathrm{PA}$ & NA & WE & PD & PA & NA & WE & PD & PA & NA & WE & PD \\
\hline \multirow{4}{*}{ Gratitude } & PA & & & & & & & & & & & & \\
\hline & NA & $-.42 * *$ & & & & $-.95 * *$ & & & & $-.55^{* *}$ & & & \\
\hline & WE & $.67 * *$ & $-.40 * *$ & & & $.56^{* *}$ & $-.70 * *$ & & & $.37 * *$ & .04 & & \\
\hline & PD & -.24 & .02 & -.08 & & $-.39 * *$ & $.39 * *$ & $-.44 * *$ & & .17 & -.17 & -.09 & \\
\hline \multirow{4}{*}{ Job Diary } & PA & & & & & & & & & & & & \\
\hline & NA & -.27 & & & & $-.29 *$ & & & & -.16 & & & \\
\hline & WE & $.65^{* *}$ & -.27 & & & $.72 * *$ & .06 & & & $.60^{* *}$ & .05 & & \\
\hline & PD & -.18 & $.65^{* *}$ & -.27 & & .24 & -.20 & .25 & & .24 & .07 & $38 * *$ & \\
\hline \multirow{4}{*}{ No Exposure } & PA & & & & & & & & & & & & \\
\hline & NA & $-.29 *$ & & & & $-.35^{*}$ & & & & $-.39 * *$ & & & \\
\hline & WE & $.74 * *$ & -.20 & & & $.63^{* *}$ & $-.33 *$ & & & $.51 * *$ & $-.28 *$ & & \\
\hline & PD & .04 & .06 & .05 & & -.24 & .04 & .01 & & -.24 & -.00 & .08 & \\
\hline
\end{tabular}

Notes. PA, NA, WE, and PD stand for positive affect, negative affect, work engagement, and perceived damage.

$*$ and $* *$ indicate a significance at 0.05 level and 0.01 level, respectively. 


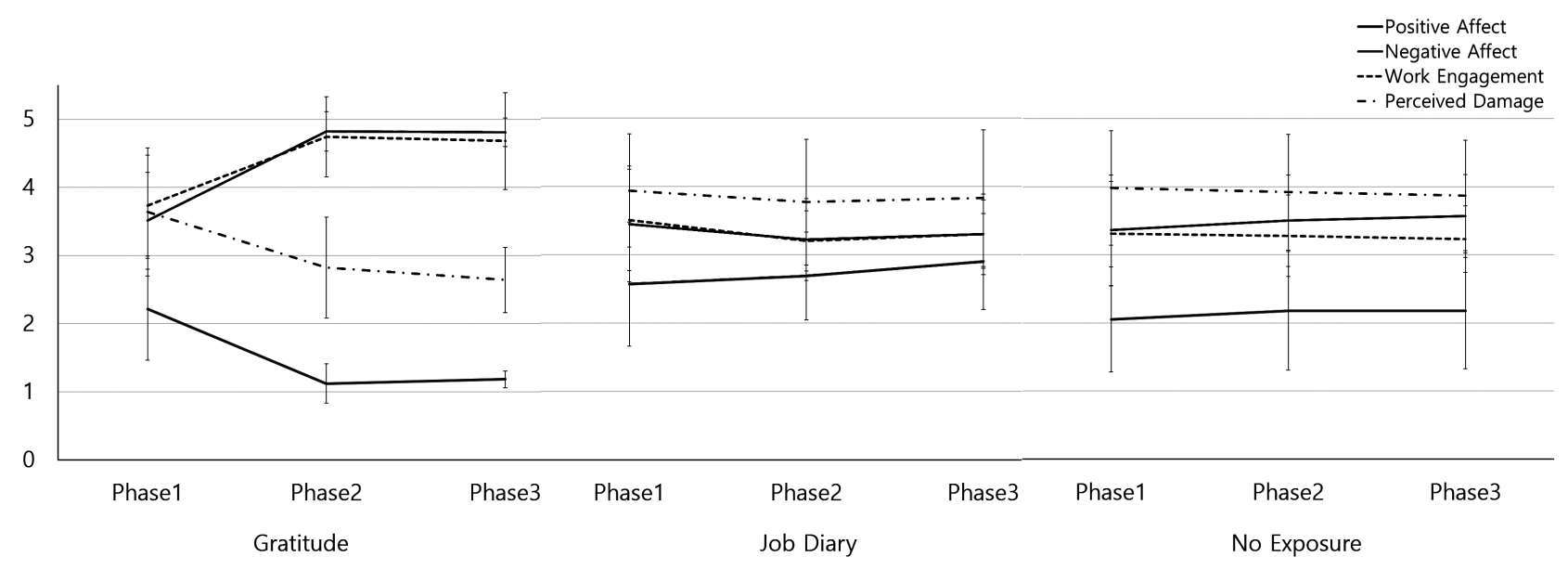

Fig. (1). Positive affect, negative affect, work engagement and Perceived Damage through phases 1, 2, and 3 in Gratitude, Job Diary, and No Exposure groups (phases 1, 2, and 3 indicate Before Intervention, Intervention, and Post-Intervention, respectively).

\section{DISCUSSION}

An association between gratitude and well-being and emotional functioning has been well documented [2], but not all of the studies stated improvement of emotional functioning and furthermore, work engagement [28]. The present study was set out to examine again an association of gratitude with work engagement and perception of damage with survivors against natural disasters. In addition, we may have a hint as to a possible causal mechanism of gratitude by introducing gratitude intervention with proper control groups.

The results showed that gratitude intervention seemed effective at least during the intervention period. All of the dependent variables showed significant increases between phases 1 and 2 in gratitude. In addition, the unique associations of perceived damage appeared with positive affect, negative affect, and work engagement for gratitude: a negative relation with positive affect and work engagement and a positive relation with negative affect.

These findings support the hypothesis: the effect of gratitude intervention was clear between the phases 1 and 2, and at phase 3 , the level of dependent variables stayed about the same as phase 2. In other words, when thinking about being grateful and doing an appropriate exercise, the effect of gratitude was apparent with better emotional functioning, increased work engagement, and decreased perceived damage of nature as participants went through gratitude intervention. Furthermore, even under the condition of a natural disaster, gratitude might play an important role.

More importantly, this effect lasted at least one month after the intervention. Participants showed a similar level of positive and negative affect, work engagement, and perception of damage. It is noteworthy that only two weeks of gratitude exercise was strong enough to maintain its effect. Even though it is unclear whether two weeks were enough for making a habit of gratitude exercise, this finding suggests the importance of making a habit of expressing gratitude in everyday life.

Apparently, the type of intervention, a daily listing of grateful things, used in this study, brought significant changes in their effect, perception, and work engagement. By listing 3 nice people, participants had a chance of deeply thinking about what they should be grateful for and why they should be appreciative for. Therefore, participants may have started to think in a positive way and possibly reappraise their experience, thus leading them to behave adaptively. Future studies need to test the effectiveness of other types of intervention, such as grateful contemplation and expressing gratitude.

The findings of this study were consistent with those in previous studies $[15,29]$. Gratitude has been reported to be associated with less physical symptoms [4, 18], and with positive affects $[13,15]$. It is expected that changes in physical and emotional aspects could make people think more positively and see good things even from the negative point of views [9], resulting in less perceived damage and improved work engagement. As expected, gratitude intervention in this study brought increased positive affect, better work engagement, and decreased perception of the damage from natural disasters. Gratitude may lead survivors to behave and see their life in an adaptive way, bringing a flexible way of thinking.

Current findings make an important contribution to the gratitude research. First, there were several studies investigating the association between gratitude and other variables, such as well-being, PTSD symptoms, and psychological impairment with traumatized populations [13] [12, 15]. However, studies on those with psychological impairment from traumatic events are scanty and no study has investigated the effect of gratitude on other variables with a prospective longitudinal design and gratitude intervention. Second, the effect of gratitude was properly tested in this study because the gratitude intervention group was compared with the daily hassle group and no treatment group. Otherwise, the possibility of participant expectancy could not be completely eliminated.

\section{CONCLUSION}

The present study showed that a simple intervention of 
gratitude is helpful for survivors from a natural disaster. It is very meaningful in terms of its applicability as well as gratitude research. First, the design of this study is very informative for gratitude intervention research, especially with the comparison to the control group. Second, an association between gratitude and work engagement and perception of damage was shown, even though their exact causal mechanism is yet to be cleared up. Third, the effect of gratitude intervention lasted a month after intervention. This finding can be used for the development of therapeutic programs for those who have experienced traumatic events.

These findings need to be interpreted in the context of several limitations. First, the sample size was relatively small due to the difficulty of recruitment. Second, the function of gratitude could not be fully stated without pre-disaster data, which may not be possible. Third, the effect of gratitude intervention did not appear for the post-intervention period. Future researches should be designed to overcome these limitations.

\section{ETHICS APPROVAL AND CONSENT TO PARTI- CIPATE}

This study was approved by the Institutional Review Board of Ajou University, South Korea under ethical approval number 201512-HR-SB-001-02.

\section{HUMAN AND ANIMAL RIGHTS}

No Animals were used in this research. All human research procedures followed were in accordance with the ethical standards of the committee responsible for human experimentation (institutional and national), and with the Helsinki Declaration of 1975, as revised in 2013.

\section{CONSENT FOR PUBLICATION}

Informed consent was taken from all the participants when they were enrolled.

\section{AVAILABILITY OF DATA AND MATERIALS}

The data supporting the findings of the article is available in the Naver Cloud at http://naver.me/5zHbojkZ.

\section{FINDING}

None.

\section{CONFLICT OF INTEREST}

The authors declare no conflict of interest, financial or otherwise.

\section{ACKNOWLEDGEMENTS}

Declared none.

\section{REFERENCES}

[1] Roberts RC. The blessings of gratitude: A conceptual analysis.Emmons RA, McCullough ME, Eds The Psychology of Gratitude, Oxford University Press . 2004; pp. 58-78.

[2] Wood AM, Froh JJ, Geraghty AWA. Gratitude and well-being: A review and theoretical integration. Clin Psychol Rev 2010; 30(7): 890-905. [http://dx.doi.org/10.1016/j.cpr.2010.03.005] [PMID: 20451313]

[3] Sansone RA, Sansone LA. Gratitude and well being: The benefits of appreciation. Psychiatry (Edgmont Pa) 2010; 7(11): 18-22. [PMID: 21191529]

[4] Emmons RA, McCullough ME. Counting blessings versus burdens: An experimental investigation of gratitude and subjective well-being in daily life. J Pers Soc Psychol 2003; 84(2): 377-89.

[http://dx.doi.org/10.1037/0022-3514.84.2.377] [PMID: 12585811]

[5] Watkins PC, Cruz L, Holben H, Kolts RL. Taking care of business? Grateful processing of unpleasant memories. J Posit Psychol 2008; 3: 87-99.

[http://dx.doi.org/10.1080/17439760701760567]

[6] Lambert NM, Graham SM, Fincham FD, Stillman TF. A changed perspective: How gratitude can affect sense of coherence through positive reframing. J Posit Psychol 2009; 4: 461-70.

[http://dx.doi.org/10.1080/17439760903157182]

[7] Deutsch CJ. Self-reported sources of stress among psychotherapists. Prof Psychol Res Pr 1984; 15: 833-45.

[http://dx.doi.org/10.1037/0735-7028.15.6.833]

[8] Wood AM, Maltby J, Gillett R, Linley PA, Joseph S. The role of gratitude in the development of social support, stress, and depression: Two longitudinal studies. J Res Pers 2008; 42: 854-71.

[http://dx.doi.org/10.1016/j.jrp.2007.11.003]

[9] Kaplan S, Bradley-Geist JC, Ahmad A, Anderson A, Hargrove AK, Lindsey A. A test of two positive psychology interventions to increase employee well-being. J Bus Psychol 2014; 29: 367-80.

[http://dx.doi.org/10.1007/s10869-013-9319-4]

[10] Sheldon KM, Lyubomirsky S. How to increase and sustain positive emotion: The effects of expressing gratitude and visualizing best possible selves. J Posit Psychol 2006; 1: 73-82. [http://dx.doi.org/10.1080/17439760500510676]

[11] Emmons RA, McCullough ME. The psychology of gratitude. New York, NY: Oxford University Press 2004.

[http://dx.doi.org/10.1093/acprof:oso/9780195150100.001.0001]

[12] Vernon LL, Dillon JM, Steiner ARW. Proactive coping, gratitude, and posttraumatic stress disorder in college women. Anxiety Stress Coping 2009; 22(1): 117-27.

[http://dx.doi.org/10.1080/10615800802203751] [PMID: 18791902]

[13] Kashdan TB, Uswatte G, Julian T. Gratitude and hedonic and eudaimonic well-being in Vietnam war veterans. Behav Res Ther 2006; 44(2): 177-99.

[http://dx.doi.org/10.1016/j.brat.2005.01.005] [PMID: 16389060]

[14] McCanlies EC, Gu JK, Andrew ME, Violanti JM. The effect of social support, gratitude, resilience and satisfaction with life on depressive symptoms among police officers following Hurricane Katrina. Int $\mathrm{J}$ Soc Psychiatry 2018; 64(1): 63-72.

[http://dx.doi.org/10.1177/0020764017746197] [PMID: 29334848]

[15] Lies J, Mellor D, Hong RY. Gratitude and personal functioning among earthquake survivors in Indonesia. J Posit Psychol 2014; 9: 290-305. [http://dx.doi.org/10.1080/17439760.2014.902492]

[16] Zhou X, Wu X. Understanding the roles of gratitude and social support in posttraumatic growth among adolescents after Ya'an earthquake: A longitudinal study. Pers Individ Dif 2016; 101: 4-8.

[http://dx.doi.org/10.1016/j.paid.2016.05.033]

[17] Layous K, Lee H, Choi I, Lyubomirsky S. Culture matters when designing a successful happiness-increasing activity: A comparison of the United States and South Korea. J Cross Cult Psychol 2012; 44: 1294-303.

[http://dx.doi.org/10.1177/0022022113487591]

[18] Froh JJ, Kashdan TB, Mallen-Ozimkowski K, Miller N. Who benefits the most from a gratitude intervention in children and adolescents? Examining positive affect as a moderator. J Posit Psychol 2009; 4: 408-22.

[http://dx.doi.org/10.1080/17439760902992464]

[19] Geraghty AWA, Wood AM, Hyland ME. Attrition from self-directed interventions: investigating the relationship between psychological predictors, intervention content and dropout from a body dissatisfaction intervention. Soc Sci Med 2010; 71(1): 30-7. a [http://dx.doi.org/10.1016/j.socscimed.2010.03.007] [PMID: 20400220]

[20] Henrie P. The effects of gratitude on divorce adjustment and wellbeing of middle-aged divorced women. : Ph.D. diss., Dept. of Educational Psychology, University of Utah2007.

[21] Mallen-Ozimkowski K. The gratitude visit in children and adolescents: An investigation of gratitude and subjective well-being. : Psy.D. diss. Dept. of Psychology, Hofstra University 2008.

[22] Watkins PC, Woodward K, Stone T, Kolts RL. Gratitude and 
happiness: Development of a measure of gratitude, and relationships with subjective well-being. Soc Behav Personal 2003; 31: 431-51. [http://dx.doi.org/10.2224/sbp.2003.31.5.431]

[23] Seligman MEP, Steen TA, Park N, Peterson C. Positive psychology progress: empirical validation of interventions. Am Psychol 2005; 60(5): 410-21.

[http://dx.doi.org/10.1037/0003-066X.60.5.410] [PMID: 16045394]

[24] Lyubomirsky S, Tkach C, Yelverton J. Pursuing sustained happiness through random acts of kindness and counting one's blessings: Tests of two six-week interventions Unpublished raw data. Dept. of Psychology, University of California, Riverside 2004.

[25] Geraghty AWA, Wood AM, Hyland ME. Dissociating the facets of hope: Agency and pathways predict attrition from unguided self-help in opposite directions. J Res Pers 2010; 44: 155-8. b

[http://dx.doi.org/10.1016/j.jrp.2009.12.003]
[26] Van Katwyk PT, Fox S, Spector PE, Kelloway EK. Using the JobRelated Affective Well-Being Scale (JAWS) to investigate affective responses to work stressors. J Occup Health Psychol 2000; 5(2): 219-30.

[http://dx.doi.org/10.1037/1076-8998.5.2.219] [PMID: 10784286]

[27] Schaufeli WB, Salanova M, González-romá V, Bakker AB. The measurement of engagement and burnout: A two sample confirmatory factor analytic approach. J Happiness Stud 2002; 3: 71-92.

[http://dx.doi.org/10.1023/A:1015630930326]

[28] Komase Y, Watanabe K, Imamura K, Kawakami N. Effects of a newly developed gratitude intervention program on work engagement among Japanese workers. J Occup Environ Med 2019; 61(9): e378-83. [http://dx.doi.org/10.1097/JOM.0000000000001661] 31306267]

[29] Lyubomirsky S, Layous K. How do simple positive activities increase well-being? Psychol Sci 2013; 22: 57-62.

\section{C) $2020 \mathrm{Kim}$ et al.}

This is an open access article distributed under the terms of the Creative Commons Attribution 4.0 International Public License (CC-BY 4.0), a copy of which is available at: https://creativecommons.org/licenses/by/4.0/legalcode. This license permits unrestricted use, distribution, and reproduction in any medium, provided the original author and source are credited. 